\title{
Seleção precoce para produção de grãos em café arábica pela avaliação de caracteres morfológicos
}

\author{
Alexsandro Lara Teixeira(1), Flávia Maria Avelar Gonçalves ${ }^{(2)}$, Juliana Costa de Rezende(3), \\ Samuel Pereira de Carvalho(2), Antônio Alves Pereira( ${ }^{(3)}$, Bráulio Fabiano Xavier de Moraes $^{(2)}$ \\ e Luíz Gustavo Vieira Teixeira(2)
}

\begin{abstract}
(1)Embrapa Rondônia, BR 364, Km 5,5, Zona Rural, Caixa Postal 127, CEP 76815-800 Porto Velho, RO. E-mail: alexteixeira@cpafro.embrapa.br (2)Universidade Federal de Lavras, Caixa Postal 3037, CEP 37200-000 Lavras, MG. E-mail: avelar@dbi.ufla.br, samuelpc@dag.ufla.br, brauliofxm@hotmail.com, apocalnet16@hotmail.com ${ }^{(3)}$ Epamig, Campus da Ufla, Rodovia Lavras-ljaci, Km 02, Caixa Postal 176, CEP 37200-000 Lavras, MG. E-mail: julianacosta@epamig.br, pereira@epamig.br
\end{abstract}

Resumo - O objetivo deste trabalho foi avaliar a viabilidade da seleção precoce em café arábica, por meio do emprego de correlações entre caracteres morfológicos e de produção de grãos. Foram avaliados 269 acessos de Coffea arabica, entre cultivares, híbridos e genótipos selvagens, oriundos do banco de germoplasma de café da Epamig, em Patrocínio, MG. Utilizou-se o delineamento em blocos ao acaso, com duas repetições, no espaçamento $3,5 \times 0,8 \mathrm{~m}$, com parcelas de dez plantas. Os caracteres morfológicos foram avaliados em 2006 , 12 meses após a implantação da cultura, com as plantas ainda na fase juvenil. Os dados de produção de grãos foram referentes às safras de 2008/2009 e 2009/2010. O comprimento do primeiro ramo plagiotrópico, aos 12 meses de idade, apresentou alta correlação e alto efeito direto, em sentido favorável à produção de grãos, tendo sido o principal caráter morfológico responsável pela variação na produção de grãos. O vigor vegetativo, aos 12 meses de idade, foi a variável secundária de maior importância para explicar variações na produção de grãos. Esses caracteres podem ser utilizados efetivamente na seleção precoce para produção de grãos em café arábica.

Termos para indexação: Coffea arabica, análise de trilha, comprimento de ramo, melhoramento do cafeeiro, vigor vegetativo.

\section{Early selection for grain yield in Arabica coffee using morphological traits evaluation}

\begin{abstract}
The objective of this work was to assess the viability of early selection in Arabica coffee using the correlation between morphological traits and grain yield. Two hundred and sixty-nine accessions of Coffea arabica, among cultivars, hybrids, and wild genotypes, from Epamig's coffee germplasm bank, Patrocínio, MG, Brazil, were evaluated. A randomized complete block design was used, with two replicates, at a spacing of $3.5 \times 0.8 \mathrm{~m}$, with ten plants per plot. Morphological traits were evaluated in 2006, 12 months after planting, when plants were still at the juvenile phase. Grain yield data are from the 2008/2009 and 2009/2010 crop seasons. The length of the first plagiotropic stem, at 12 months of age, was highly correlated and showed a high direct effect in a favorable direction toward grain yield, being the main morphological trait responsible for variations in grain yield. The vegetative vigor at 12 months of age was the most important secondary variable in explaining the variations in grain yield. These traits can be used effectively in the early selection for grain yield in Arabica coffee.
\end{abstract}

Index terms: Coffea arabica, path analysis, stem length, coffee breeding, vegetative vigor.

\section{Introdução}

A busca por cultivares mais produtivas tem sido o principal foco dos programas de melhoramento do cafeeiro no Brasil (Carvalho et al., 1988, 2010; Martinez et al., 2007). O emprego da seleção indireta, com uso de caracteres correlacionados à produção de grãos, é uma estratégia que vem sendo utilizada em programas de melhoramento, pois permite maximizar os ganhos com a seleção. Essa ferramenta proporciona, aos melhoristas, uma melhor orientação na escolha das variáveis a serem utilizadas no momento da seleção (Cruz et al., 2004).

Estimativas de correlações positivas entre produtividade e caracteres morfológicos, em cafeeiro, têm sido encontradas em diversos trabalhos 
(Carvalho et al., 2010). Apesar de auxiliar no entendimento de um caráter complexo, a análise da correlação não permite determinar a importância dos efeitos diretos e indiretos dos caracteres que a compõem. Assim, não é possível constatar se sua estimativa foi estabelecida por verdadeiras relações de causa e efeito, e a interpretação direta de suas magnitudes pode resultar em equívocos na estratégia de seleção, pois a alta correlação entre dois caracteres pode ser resultado do efeito de um terceiro caráter, ou de um grupo de caracteres, sobre eles (Wright, 1921).

A análise de trilha consiste no estudo dos efeitos diretos e indiretos de caracteres sobre uma variável principal, cujas estimativas são obtidas por meio de equações de regressão, em que as variáveis são previamente padronizadas. Embora a correlação seja uma característica intrínseca a dois caracteres em dada condição experimental, sua decomposição depende do conjunto de caracteres estudados, que normalmente são avaliados pelo conhecimento prévio de suas importâncias e de possíveis inter-relações expressas em diagramas de trilha (Cruz et al., 2004). Esta técnica tem sido amplamente utilizada no melhoramento de diversas culturas; entretanto, são poucos os trabalhos desta natureza na cultura do cafeeiro.

Ao analisar os efeitos diretos e indiretos de alguns caracteres morfológicos sobre a produtividade de grãos em café, Severino et al. (2002) constataram que o vigor vegetativo e a seca de ponteiros são bons critérios de avaliação do potencial produtivo. Já em estudos com capim-elefante, Daher et al. (2004) verificaram que caracteres morfológicos, como número de perfilhos por metro linear e diâmetro de perfilhos a $10 \mathrm{~cm}$ do solo, foram capazes de melhor explicar o potencial de produção de matéria seca, tendo atuado de forma direta e inversamente proporcional sobre a variável principal, de acordo com as condições ambientais durante o crescimento. Segundo estes autores, a análise de trilha pode auxiliar o melhorista na escolha dos caracteres a serem utilizados na seleção para produtividade de grãos, com vistas à obtenção de maiores ganhos com a seleção.

A identificação de caracteres com maior efeito direto no sentido favorável à seleção é primordial para que a resposta correlacionada, por meio da seleção indireta, seja eficiente. Além disso, em se tratando de plantas perenes, a existência de correlação entre caracteres na fase juvenil e na fase produtiva pode tornar viável a realização da seleção precoce (Freitas et al., 2007).

O objetivo deste trabalho foi avaliar a viabilidade de utilização da seleção precoce em café arábica (Coffea arabica L.), por meio do emprego de correlações entre caracteres morfológicos e de produção de grãos.

\section{Material e Métodos}

$\mathrm{O}$ experimento foi realizado em Patrocínio, MG (18 56'38"S e 46059'34"W, a 972 m de altitude média). O clima da região, conforme a classificação de Köppen, é do tipo Cwa, tropical de altitude, com temperaturas médias anuais de $20,2^{\circ} \mathrm{C}$ e precipitação pluvial média de $1.620 \mathrm{~mm}$, com 65 a $70 \%$ desse total concentrados no período de dezembro a março.

Foram avaliados 269 acessos de C. arabica, representados por cultivares, híbridos e alguns genótipos selvagens introduzidos de outros países, oriundos do banco de germoplasma de café, instalado no ano de 2005, na fazenda experimental da Empresa de Pesquisa Agropecuária de Minas Gerais, em Patrocínio, MG. Utilizou-se o delineamento em blocos ao acaso, com duas repetições, no espaçamento de $3,5 \times 0,8 \mathrm{~m}$, com parcelas de dez plantas. Os caracteres morfológicos foram avaliados em 2006, 12 meses após a implantação da cultura, com as plantas ainda na fase juvenil. Os dados de produção de grãos foram referentes às safras de 2008/2009 e 2009/2010. Os experimentos foram conduzidos de acordo com as recomendações de adubação para a cultura do cafeeiro. Foram adotadas as práticas de manejo usualmente empregadas na cultura.

Os caracteres avaliados foram: vigor vegetativo, tendo-se atribuído notas de 1 a 10 para sua avaliação, em que 1 foi utilizado para plantas depauperadas, e 10 para plantas muito vigorosas; altura da planta $(\mathrm{cm})$, medida do colo da planta até a gema apical do caule; número de pares de ramos plagiotrópicos (NPRP), avaliado por meio da contagem de todos os pares de ramos laterais primários que apresentaram comprimento superior a $5 \mathrm{~cm}$; comprimento do primeiro ramo plagiotrópico (CRP), avaliado por meio da medição do primeiro ramo plagiotrópico acima do colo da planta, em cm; número de nós do primeiro ramo plagiotrópico (NRP), obtido pela contagem de todos os nós do ramo; comprimento do quarto par de folhas (CPF), em cm; largura do quarto par de folhas (LPF), em cm; e produção de grãos (café beneficiado), tendo-se determinado a produtividade de 
grãos por parcela, com posterior conversão para sacas por hectare.

Com a finalidade de atender às pressuposições da análise de variância, foram realizados os testes de homogeneidade e normalidade de variância do erro e, após verificação de que os dados atendiam às pressuposições da análise de variância, foram obtidas as estimativas de correlações genotípicas e do coeficiente de determinação genotípico.

Foi avaliado o grau de multicolinearidade da matriz de correlação das médias X'X (Montgomery \& Peck, 1981), e, para detectar as variáveis que contribuíram para o surgimento da multicolinearidade, efetuou-se a análise dos autovalores e autovetores. De acordo com Montgomery \& Peck (1981), valores de $\mathrm{NC}<100$ não constituem problema sério (multicolinearidade fraca). Se $100<\mathrm{NC}<1.000$, a multicolinearidade é de moderada a forte, e, quando $\mathrm{NC}>1.000$, há fortes indícios de multicolinearidade severa. Para contornar os efeitos da multicolinearidade sem que houvesse necessidade de descarte de variáveis, foi utilizado o método de regressão em crista (Hoerl \& Kennard, $1970)$, em que se adicionou uma variável $(\mathrm{k}=0,15)$ à diagonal da matriz $X^{\prime} X$. Com esse procedimento, foi possível obter um número de condição $(\mathrm{NC})$ menor que 100, que caracteriza multicolinearidade fraca e não compromete a análise de trilha. Posteriormente, foram realizados os desdobramentos das correlações genotípicas em efeitos diretos e indiretos por meio da análise de trilha (Wright, 1921).

Para análise dos dados, adotou-se um diagrama causal em cadeia (Figura 1). O critério adotado na elaboração do diagrama foi baseado na biologia reprodutiva do cafeeiro, tendo-se estipulado, como variáveis primárias, as diretamente relacionadas com a produção de grãos, e, como variáveis secundárias, o restante. Dessa forma, a produção de grãos foi considerada a variável principal, com NPRP, CRP e

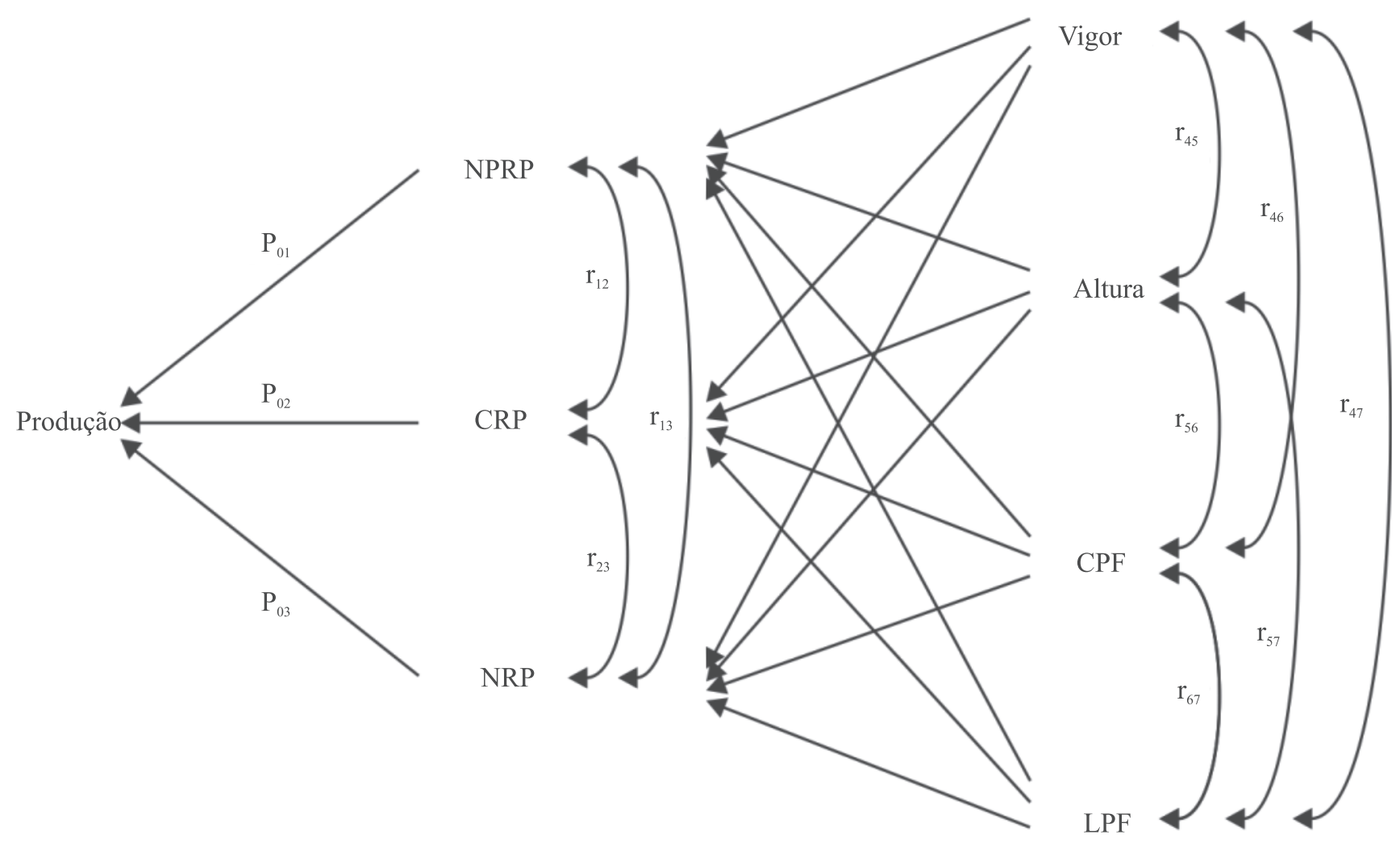

Figura 1. Diagrama causal em cadeia dos efeitos diretos e indiretos das variáveis secundárias - vigor, altura, comprimento (CPF) e largura (LPF) do quarto par de folhas - sobre a variável principal produção e sobre as variáveis primárias número de pares de ramos plagiotrópicos (NPRP), e comprimento (CRP) e número de nós do primeiro ramo plagiotrópico (NRP). A seta unidirecional indica efeito direto de cada variável explicativa, enquanto a seta bidirecional representa a interdependência de duas variáveis explicativas, cuja magnitude é quantificada pela correlação genotípica. 
$\mathrm{NRP}$, como variáveis primárias, e vigor, altura, CPF e LPF, como variáveis secundárias.

Para a avaliação dos efeitos diretos e indiretos dos caracteres secundários sobre cada caráter primário, o modelo apropriado e os sistemas de equações derivados para cada variável explicativa foram utilizados. O estudo dos efeitos dos componentes secundários sobre a variável principal produção foi realizado por meio dos desdobramentos da correlação entre a variável principal e as variáveis secundárias (Cruz et al., 2004).

Os dados obtidos referentes aos caracteres morfológicos e à produtividade de grãos foram submetidos à análise de variância, com a significância dos efeitos verificada pelo teste $\mathrm{F}$, a $5 \%$ de probabilidade. A acurácia seletiva $\left(\hat{\mathrm{r}}_{\mathrm{g} g}\right)$, determinada por meio da expressão: $\hat{\hat{x}}_{\mathrm{gg}}=(1-1 / \mathrm{F})^{0,5}$, em que F é o valor do teste $\mathrm{F}$ de Snedecor para o efeito de genótipo (Resende \& Duarte, 2007), foi estimada para aferir a precisão experimental. As análises de variância foram realizadas com o pacote estatístico SAS (SAS Institute, 1999). As estimativas de herdabilidade no sentido amplo foram obtidas pelas variâncias genéticas $\left(\sigma_{\mathrm{g}}^{2}\right)$ e fenotípicas $\left(\sigma_{\mathrm{f}}^{2}\right)$, por meio da equação $h_{\mathrm{a}}^{2}=\sigma_{\mathrm{g}}^{2} / \sigma_{\mathrm{f}}^{2}$. As correlações genotípicas e a análise de trilha foram realizadas com uso do programa Genes (Cruz, 2006).

\section{Resultados e Discussão}

Todas as características estudadas apresentaram diferenças significativas entre genótipos (Tabela 1). As estimativas de acurácia foram de alta magnitude $\left(65<\hat{\mathrm{r}}_{\mathrm{gg}}<90\right)$, o que indica boa precisão experimental. $\mathrm{O}$ uso da acurácia, como medida de precisão experimental, conforme Resende \& Duarte (2007), tem a vantagem de não depender da magnitude da média, o que proporciona maior segurança na utilização da expressão fenotípica como indicador da variação genotípica. Valores de acurácia acima de 70\% indicam alta precisão experimental.

A média da análise conjunta para produção de grãos foi de 21,70 sacas por hectare. A herdabilidade observada para o caráter foi baixa $\left(\mathrm{h}^{2}=45 \%\right)$. A baixa média registrada para produção já era esperada, em razão da alta variabilidade genética presente entre os acessos, que apresentaram produtividades de 2,70 até 63,80 sacas por hectare. Entretanto, os valores obtidos para herdabilidade são aceitáveis. Valores acima de 70\% para este parâmetro são encontrados em experimentos com cafeeiros em gerações mais avançadas ou mesmo em ensaios de valor de cultivo e uso (Carvalho et al., 1988).

Com relação aos caracteres morfológicos, a média observada para vigor vegetativo $(7,86)$ pode ser considerada alta, o que evidencia, no geral, que as plantas sob avaliação apresentavam boas condições vegetativas. Quanto à herdabilidade, o caráter altura de planta foi o que apresentou maior valor $(75 \%)$, o que mostra que, para essa característica, é possível obter maiores ganhos genéticos com a seleção (Tabela 1).

As maiores correlações foram observadas entre a produção de grãos e as variáveis comprimento do primeiro ramo plagiotrópico, vigor vegetativo, largura do quarto par de folhas e número de nós do primeiro ramo plagiotrópico (Tabela 2). Portanto, plantas de maior vigor aos 12 meses de idade e que apresentem o primeiro ramo plagiotrópico longo e com grande número de nós tendem a ser mais produtivas. $\mathrm{O}$ vigor vegetativo também apresentou alta correlação com número de pares de ramos plagiotrópicos, comprimento

Tabela 1. Resumo da análise de variância dos oito caracteres agronômicos e morfológicos avaliados em Coffea arabica.

\begin{tabular}{|c|c|c|c|c|c|c|c|c|c|}
\hline \multirow{3}{*}{$\begin{array}{l}\text { Fonte de variação } \\
\text { Blocos }\end{array}$} & \multirow{3}{*}{$\begin{array}{c}\text { GL } \\
\\
1\end{array}$} & \multicolumn{8}{|c|}{ Quadrado médio(1) } \\
\hline & & $\begin{array}{c}\text { Produção } \\
\left(\text { sacas por ha }^{-1}\right)\end{array}$ & $\begin{array}{c}\text { Vigor } \\
\text { (escala de notas) }\end{array}$ & $\begin{array}{c}\text { Altura } \\
(\mathrm{cm})\end{array}$ & NPRP & $\begin{array}{l}\text { CRP } \\
(\mathrm{cm})\end{array}$ & NRP & \multicolumn{2}{|c|}{$\begin{array}{l}\text { CPF LPF } \\
--\cdot---(\mathrm{cm})---\cdot- \\
\end{array}$} \\
\hline & & 147,76 & 0,22 & 88,27 & 80,11 & 3,28 & 175,99 & 3,76 & 0,21 \\
\hline Genótipos & 268 & $131,97 * *$ & $1,63 * *$ & $419,35^{* *}$ & $33,68 * *$ & $6,76^{* *}$ & $200,10^{* *}$ & $8,68 * *$ & $3,43 * *$ \\
\hline$\underline{\text { Resíduo }}$ & 268 & 71,43 & 0,66 & 103,09 & 12,28 & 2,57 & 82,15 & 3,03 & 1,56 \\
\hline Média & & 21,71 & 7,86 & 72,97 & 11,32 & 47,73 & 13,96 & 12,17 & 5,67 \\
\hline Acurácia seletiva (\%) & & 67,74 & 76,97 & 86,84 & 79,71 & 78,73 & 76,77 & 80,67 & 73,83 \\
\hline Herdabilidade (\%) & & 45,88 & 59,25 & 75,42 & 61,99 & 58,94 & 65,08 & 54,52 & 55,66 \\
\hline
\end{tabular}

(1)Análise conjunta das safras de 2008/2009 e 2009/2010. **Significativo pelo teste F, a 1\% probabilidade. NPRP, número de pares de ramos plagiotrópicos; CRP, comprimento do primeiro ramo plagiotrópico; NRP, número de nós do primeiro ramo plagiotrópico; CPF, comprimento do quarto par de folhas; LPF, largura do quarto par de folhas. 
do primeiro ramo plagiotrópico e número de nós do primeiro ramo plagiotrópico. Estes resultados estão de acordo com Freitas et al. (2007), que constataram que a seleção precoce, quanto ao comprimento de ramos plagiotrópicos aos 12 meses de idade, pode ser utilizada para identificação de genótipos superiores. Estes autores, no entanto, não realizaram a avaliação direta da produção de grãos e basearam suas conclusões apenas na capacidade fotossintética das plantas.

Estimativas de correlação semelhantes foram obtidas por Severino et al. (2002), para vigor vegetativo e produção de grãos $(0,90)$, em dados acumulados durante os três primeiros anos de produção. Esses resultados são indicativos de que a seleção precoce pode ser utilizada na identificação de genótipos com alto potencial produtivo e, ainda, auxiliar o melhorista nas tomadas de decisão em etapas iniciais dos programas de melhoramento.

Ao se analisar as correlações por meio do diagrama causal em cadeia (Figura 1), todas as três variáveis primárias apresentaram coeficientes de correlação acima de 0,65, com a variável primária produção (Tabela 3). Já entre os componentes primários e secundários, a variável secundária vigor apresentou alta correlação genotípica com as variáveis primárias, com estimativas acima de 0,83 (Tabela 4). Para a variável altura, foi observada alta correlação apenas com o caráter CRP. Esse resultado assemelha-se ao encontrado por Carvalho et al. (2010), que observaram alta correlação entre altura da planta e comprimento dos ramos plagiotrópicos $(0,92)$, em plantas já em fase de produção. É interessante ressaltar que, para o caráter

Tabela 2. Estimativa dos coeficientes de correlação genotípica entre oito caracteres agronômicos e morfológicos avaliados em Coffea arabica.

\begin{tabular}{|c|c|c|c|c|c|c|c|c|}
\hline Variáveis ${ }^{(1)}$ & Produção & Vigor & Altura & NPRP & CRP & NRP & CPF & LPF \\
\hline Produção & 1,00 & 0,98 & 0,73 & 0,69 & 0,99 & 0,75 & 0,63 & 0,78 \\
\hline Vigor & & 1,00 & 0,54 & 0,94 & 0,90 & 0,84 & 0,49 & 0,65 \\
\hline Altura & & & 1,00 & 0,44 & 0,86 & 0,39 & 0,46 & 0,38 \\
\hline NPRP & & & & 1,00 & 0,71 & 0,88 & 0,23 & 0,39 \\
\hline CRP & & & & & 1,00 & 0,71 & 0,55 & 0,61 \\
\hline NRP & & & & & & 1,00 & 0,11 & 0,34 \\
\hline $\mathrm{CPF}$ & & & & & & & 1,00 & 0,88 \\
\hline LPF & & & & & & & & 1,00 \\
\hline
\end{tabular}

(1)NPRP, número de pares de ramos plagiotrópicos; CRP, comprimento do primeiro ramo plagiotrópico; NRP, número de nós do primeiro ramo plagiotrópico; CPF, comprimento do quarto par de folhas; LPF, largura do quarto par de folhas. altura de planta, os programas de melhoramento têm preconizado plantas de porte médio, em razão das práticas culturais de plantios adensados e colheita mecanizada (Androcioli Filho, 2002), atualmente comuns.

Algumas variáveis, apesar de terem apresentado alta associação com a variável principal, podem não ser a causa determinante das variações sobre o caráter de interesse. Nessas situações, a concentração de esforços na seleção desta variável poderá não resultar em ganhos satisfatórios na variável principal (Cruz et al., 2004). Assim, para um melhor entendimento da inter-relação entre os caracteres, realizou-se o desdobramento dos coeficientes de correlação (análise de trilha), com o objetivo de fornecer uma medida da influência de cada causa e seu efeito. Os desdobramentos foram realizados em conformidade com o diagrama causal em cadeia (Figura 1).

As magnitudes e os sinais dos efeitos diretos e indiretos das variáveis primárias sobre a variável principal produção encontram-se na Tabela 3. Ao verificar os efeitos diretos e indiretos por meio das vias de associação (Figura 1), é possível observar que apenas a variável CRP teve efeito direto de elevada magnitude. As variáveis NPRP e NRP mostraram

Tabela 3. Estimativa dos efeitos diretos e indiretos das três variáveis primárias sobre a variável principal produção de $\operatorname{grãos}^{(1)}$.

\begin{tabular}{|c|c|c|c|}
\hline \multirow[t]{2}{*}{ Via de associação } & \multicolumn{2}{|c|}{ Coeficiente de trilha } & \multirow{2}{*}{$\begin{array}{l}\text { Coeficiente de } \\
\text { correlação }\left(r_{g}\right)\end{array}$} \\
\hline & Efeito direto & Efeito indireto & \\
\hline & \multicolumn{3}{|c|}{ Número de pares de ramos plagiotrópicos } \\
\hline Efeito direto sobre produção & $-0,02$ & - & - \\
\hline Efeito indireto via CRP & - & 0,53 & - \\
\hline Efeito indireto via NRP & - & 0,18 & - \\
\hline \multirow[t]{2}{*}{ Total } & - & - & 0,69 \\
\hline & \multicolumn{3}{|c|}{ Comprimento do $1^{\circ}$ ramo plagiotrópico } \\
\hline Efeito direto sobre produção & 0,74 & - & - \\
\hline Efeito indireto via CRP & - & $-0,01$ & - \\
\hline Efeito indireto via NRP & - & 0,15 & - \\
\hline \multirow[t]{2}{*}{ Total } & - & - & 0,99 \\
\hline & \multicolumn{3}{|c|}{ Número de nós no $1^{\circ}$ ramo plagiotrópico } \\
\hline Efeito direto sobre produção & 0,21 & - & - \\
\hline Efeito indireto via CRP & - & $-0,02$ & - \\
\hline Efeito indireto via NRP & - & 0,53 & - \\
\hline Total & - & - & 0,75 \\
\hline Coeficiente de determinação & & 0,88 & \\
\hline Efeito residual & & 0,35 & \\
\hline
\end{tabular}

(1)NPRP, número de pares de ramos plagiotrópicos; CRP, comprimento do primeiro ramo plagiotrópico; NRP, número de nós do primeiro ramo plagiotrópico. 
pequeno efeito direto sobre a produção, tendo atuado de forma indireta. Já a variável CRP, apresentou efeito direto expressivo sobre a produção. Isso mostra que, apesar de todas essas variáveis primárias apresentarem alta correlação com a produção de grãos (Tabela 2), apenas a variável CRP tem efeito direto considerável sobre esta. Assim, no processo de seleção precoce, o comprimento do primeiro ramo plagiotrópico, aos 12 meses de idade, pode ser utilizado pelo melhorista na identificação de genótipos promissores.

Situações contrárias à exposta podem ocorrer, como observado por Carvalho et al. (2010), que verificaram baixas correlações da produtividade de grãos com as variáveis número e comprimento de ramos plagiotrópicos. Nesse caso, seria interessante o emprego da análise de trilha para verificar as relações de causa e

Tabela 4. Estimativa dos efeitos diretos e indiretos das quatro variáveis secundárias sobre as três variáveis primárias.

\begin{tabular}{|c|c|c|c|}
\hline \multirow{2}{*}{ Via de associação } & \multicolumn{3}{|c|}{ Variáveis primárias $^{(1)}$} \\
\hline & NPRP & CRP & NRP \\
\hline & \multicolumn{3}{|c|}{ Vigor } \\
\hline Efeito direto & 0,90 & 0,51 & 0,79 \\
\hline Efeito indireto altura & 0,02 & 0,26 & 0,04 \\
\hline Efeito indireto $\mathrm{CPF}$ & $-0,07$ & 0,01 & $-0,16$ \\
\hline Efeito indireto LPF & $-0,05$ & 0,05 & 0,05 \\
\hline \multirow[t]{2}{*}{ Total $\left(\mathrm{r}_{\mathrm{g}}\right)$} & 0,94 & 0,90 & 0,84 \\
\hline & \multicolumn{3}{|c|}{ Altura } \\
\hline Efeito direto & 0,04 & 0,48 & 0,07 \\
\hline Efeito indireto altura & 0,49 & 0,28 & 0,43 \\
\hline Efeito indireto $\mathrm{CPF}$ & $-0,07$ & 0,01 & $-0,15$ \\
\hline Efeito indireto LPF & $-0,03$ & 0,03 & 0,03 \\
\hline \multirow[t]{2}{*}{ Total $\left(\mathrm{r}_{\mathrm{g}}\right)$} & 0,44 & 0,86 & 0,39 \\
\hline & \multicolumn{3}{|c|}{ Comprimento do $4^{\circ}$ par de folhas } \\
\hline Efeito direto & $-0,14$ & 0,01 & $-0,33$ \\
\hline Efeito indireto altura & 0,44 & 0,25 & 0,39 \\
\hline Efeito indireto $\mathrm{CPF}$ & 0,02 & 0,22 & 0,03 \\
\hline Efeito indireto LPF & $-0,06$ & 0,07 & 0,07 \\
\hline \multirow[t]{2}{*}{ Total $\left(\mathrm{r}_{\mathrm{g}}\right)$} & 0,23 & 0,55 & 0,11 \\
\hline & \multicolumn{3}{|c|}{ Largura do $4^{\circ}$ par de folhas } \\
\hline Efeito direto & $-0,07$ & 0,07 & 0,07 \\
\hline Efeito indireto altura & 0,59 & 0,33 & 0,52 \\
\hline Efeito indireto $\mathrm{CPF}$ & 0,02 & 0,18 & 0,03 \\
\hline Efeito indireto LPF & $-0,13$ & 0,01 & $-0,29$ \\
\hline Total $\left(\mathrm{r}_{\mathrm{g}}\right)$ & 0,39 & 0,61 & 0,34 \\
\hline Coeficiente de determinação & 0,80 & 0,92 & 0,71 \\
\hline Efeito residual & 0,43 & 0,28 & 0,41 \\
\hline
\end{tabular}

(1)NPRP, número de pares de ramos plagiotrópicos; CRP, comprimento do primeiro ramo plagiotrópico; NRP, número de nós do primeiro ramo plagiotrópico; CPF, comprimento do quarto par de folhas; LPF, largura do quarto par de folhas. $\mathrm{r}_{\mathrm{g}}$, correlação genotípica. efeito desses caracteres, já que, biologicamente, esses componentes devem estar estreitamente relacionados com a produção de grãos (Cruz et al., 2004).

O coeficiente de determinação do modelo da análise de trilha, em questão, foi elevado $\left(\mathrm{R}^{2}=0,88\right)$, o que mostra que as variações na variável principal são, em grande parte, explicadas por esse arranjo causal (Tabela 3). Cabe destacar que, em determinadas situações, valores maiores que o valor absoluto 1,0 podem ocorrer em consequência do modelo utilizado na estimação das variâncias e das covariâncias, que determinam a correlação (Cruz et al., 2004). Por meio da matriz de correlação entre as variáveis primárias e a principal, registrou-se um diagnóstico de multicolinearidade fraca $(\mathrm{NC}=23,12)$, o que não denota problemas nas análises. $\mathrm{Na}$ presença de multicolinearidade, as variâncias associadas aos estimadores dos coeficientes de trilha podem atingir valores excessivamente altos, o que os torna pouco confiáveis. Além disso, as estimativas dos parâmetros podem assumir valores absurdos ou sem nenhuma coerência com o fenômeno biológico estudado (Cruz et al., 2004; Rodrigues et al., 2010).

No desdobramento das correlações entre as estimativas dos efeitos diretos e indiretos das quatro variáveis secundárias sobre as três variáveis primárias, conforme o diagrama causal em cadeia (Figura 1), verificou-se que o caráter vigor teve alta magnitude de efeitos diretos sobre as três variáveis primárias, com valores acima de 0,51 , tendo chegado a 0,90 sobre NPRP (Tabela 4). O caráter vigor apresentou altas correlações e altos efeitos diretos sobre os três caracteres primários, o que o indica que pode ser utilizado na seleção destes caracteres e, por consequência, na seleção para produção de grãos. A variável secundária altura mostrou efeito direto elevado sobre a variável CRP. Já os caracteres CPF e LPF, apresentaram baixa correlação com NPRP e NRP; porém, seus efeitos indiretos via vigor superaram a magnitude dos seus respectivos efeitos residuais (Tabela 4). A variável CPF foi a que apresentou o maior efeito direto negativo, tendo atuado em sentido desfavorável sobre a variável NRP $(-0,33)$. Os coeficientes de determinação $\left(\mathrm{R}^{2}\right)$ da análise de trilha, neste caso, foram maiores que 0,70 , o que torna possível inferir que o modelo causal explicou bem as variações encontradas para as três variáveis primárias. O número de condição (NC) obtido foi de 42,01, o que indica multicolinearidade fraca entre as variáveis. 
Nas análises do efeito total, pode-se concluir que, entre os caracteres secundários, o vigor foi o que apresentou maior relação com produção (Tabela 5), com efeito direto total de elevada magnitude $(0,57)$. Verificase, também, que a influência desse caráter sobre os componentes primários foi diferente para NPRP e CRP. A variável LPF apresentou efeito indireto considerável via vigor $(0,37)$, o que ressalta a importância da variável vigor sobre a variável principal. Severino et al. (2002) também observaram que, além da alta correlação, há grande efeito direto positivo entre o vigor vegetativo e a produção de grãos. Esse fato explica porque o vigor vegetativo está entre as características mais utilizadas para estimação da capacidade produtiva de cafeeiros (Carvalho et al., 2010).

Por meio das variáveis secundárias, pode-se inferir que serão efetivos os ganhos indiretos para produção de grãos, via resposta correlacionada por seleção quanto

Tabela 5. Estimativa dos efeitos diretos e indiretos das quatro variáveis secundárias sobre as três variáveis primárias e a variável principal produção.

\begin{tabular}{|c|c|c|c|c|c|}
\hline \multirow[t]{2}{*}{ Via de associação } & \multicolumn{3}{|c|}{ Variáveis primárias ${ }^{(1)}$} & \multirow{2}{*}{$\begin{array}{l}\text { Efeito } \\
\text { residual }\end{array}$} & \multirow{2}{*}{$\begin{array}{c}\text { Efeito total } \\
\text { produção }\end{array}$} \\
\hline & NPRP & CRP & NRP & & \\
\hline & \multicolumn{5}{|c|}{ Vigor } \\
\hline Efeito direto & $-0,02$ & 0,38 & 0,16 & 0,04 & 0,57 \\
\hline Efeito indireto altura & 0,00 & 0,19 & 0,01 & $-0,05$ & 0,15 \\
\hline Efeito indireto $\mathrm{CPF}$ & 0,00 & 0,00 & $-0,03$ & 0,02 & $-0,01$ \\
\hline Efeito indireto LPF & 0,00 & 0,04 & 0,01 & 0,13 & 0,18 \\
\hline \multirow[t]{2}{*}{ Total } & $-0,02$ & 0,67 & 0,17 & 0,15 & 0,98 \\
\hline & \multicolumn{5}{|c|}{ Altura } \\
\hline Efeito direto & 0,00 & 0,36 & 0,02 & $-0,09$ & 0,28 \\
\hline Efeito indireto altura & $-0,01$ & 0,21 & 0,09 & 0,02 & 0,31 \\
\hline Efeito indireto CPF & 0,00 & 0,00 & $-0,03$ & 0,02 & $-0,01$ \\
\hline Efeito indireto LPF & 0,00 & 0,02 & 0,01 & 0,08 & 0,11 \\
\hline \multirow[t]{2}{*}{ Total } & $-0,01$ & 0,64 & 0,08 & 0,02 & 0,73 \\
\hline & \multicolumn{5}{|c|}{ Comprimento do $4^{\circ}$ par de folhas } \\
\hline Efeito direto & 0,00 & 0,01 & $-0,07$ & 0,03 & $-0,02$ \\
\hline Efeito indireto altura & $-0,01$ & 0,19 & 0,08 & 0,02 & 0,28 \\
\hline Efeito indireto CPF & 0,00 & 0,16 & 0,01 & $-0,04$ & 0,13 \\
\hline Efeito indireto LPF & 0,00 & 0,05 & 0,01 & 0,18 & 0,25 \\
\hline \multirow[t]{2}{*}{ Total } & 0,00 & 0,41 & 0,02 & 0,20 & 0,63 \\
\hline & \multicolumn{5}{|c|}{ Largura do $4^{\circ}$ par de folhas } \\
\hline Efeito direto & 0,00 & 0,06 & 0,02 & 0,21 & 0,28 \\
\hline Efeito indireto altura & $-0,01$ & 0,25 & 0,11 & 0,03 & 0,37 \\
\hline Efeito indireto CPF & 0,00 & 0,14 & 0,01 & $-0,03$ & 0,11 \\
\hline Efeito indireto LPF & 0,00 & 0,01 & $-0,06$ & 0,03 & $-0,02$ \\
\hline Total & $-0,01$ & 0,45 & 0,07 & 0,26 & 0,78 \\
\hline
\end{tabular}

(1)NPRP, número de pares de ramos plagiotrópicos; CRP, comprimento do primeiro ramo plagiotrópico; NRP, número de nós do primeiro ramo plagiotrópico; $\mathrm{CPF}$, comprimento do quarto par de folhas; LPF, largura do quarto par de folhas. a vigor. Esse caráter tem como vantagem adicional ter efeito direto positivo sobre CRP, que, entre os componentes primários, é o de maior efeito direto sobre a produção de grãos.

Ao se compararem os resultados obtidos entre as estimativas de correlação genotípica e as do coeficiente de trilha, percebe-se que é possível identificar quais são as variáveis que exercem maior influência sobre o caráter em questão, após os desdobramentos da correlação em efeitos diretos e indiretos. Além disso, a utilização da seleção precoce torna o processo mais dinâmico e eficiente, e concentra esforços nas variáveis que proporcionarão maiores ganhos com a seleção indireta.

\section{Conclusão}

O comprimento do primeiro ramo plagiotrópico e o vigor vegetativo, aos 12 meses de idade, podem ser utilizados efetivamente na seleção precoce quanto à produção de grãos, em café arábica.

\section{Referências}

ANDROCIOLI FILHO, A. Café adensado: espaçamentos e cuidados no manejo da lavoura. Londrina: Iapar, 2002. 32p. (Iapar. Circular, 121).

CARVALHO,A.;FAZUOLI,L.C.; MAZZAFERA, P. Produtividade de progênies derivadas de hibridação dos cultivares Laurina e Mundo Novo. Bragantia, v.47, p.213-222, 1988.

CARVALHO, A.M. de; MENDES, A.N.G.; CARVALHO, G.R.; BOTELHO, C.E.; GONÇALVES, F.M.A.; FERREIRA, A.D. Correlação entre crescimento e produtividade de cultivares de café em diferentes regiões de Minas Gerais, Brasil. Pesquisa Agropecuária Brasileira, v.45, p.269-275, 2010.

CRUZ, C.D. Programa Genes: estatística experimental e matrizes. Viçosa: UFV, 2006. 285p.

CRUZ, C.D.; REGAZZI, A.J.; CARNEIRO, P.C.S. Análise de trilha. In: CRUZ, C.D.; REGAZZI, A.J.; CARNEIRO, P.C.S. (Ed.). Modelos biométricos aplicados ao melhoramento. Viçosa: UFV, 2004. p.180-193.

DAHER, R.F.; PEREIRA, A.V.; PEREIRA, M.G.; LÉDO, F.J. da S.; AMARAL JUNIOR, A.T. do; ROCABADO, J.M.A.; FERREIRA, C.F.; TARDIN, F.D. Análise de trilha de caracteres forrageiros do capim-elefante (Pennisetum purpureum Schum.). Ciência Rural, v.34, p.1531-1535, 2004.

FREITAS, Z.M.T.S. de; OLIVEIRA, F.J. de; CARVALHO, S.P. de; SANTOS, V.F. dos; SANTOS, J.P. de O. Avaliação de caracteres quantitativos relacionados com o crescimento vegetativo entre cultivares de café arábica de porte baixo. Bragantia, v.66, p.267-275, 2007. 
HOERL, A.E.; KENNARD, R.W. Ridge regression: applications to nonorthogonal problems. Technometrics, v.12, p.69-82, 1970 .

MARTINEZ, H.E.P.; AUGUSTO, H.S.; CRUZ, C.D.; PEDROSA, A.W.; SAMPAIO, N.F. Crescimento vegetativo de cultivares de café (Coffea arabica L.) e sua correlação com a produção em espaçamentos adensados. Acta Scientiarum. Agronomy, v.29, p.481-489, 2007.

MONTGOMERY, D.C.; PECK, E.A. Introduction to linear regression analysis. New York: John Wiley, 1981. 504p.

RESENDE, M.D.V. de; DUARTE, J.B. Precisão e controle de qualidade em experimentos de avaliação de cultivares. Pesquisa Agropecuária Tropical, v.37, p.182-194, 2007.
RODRIGUES, G.B.; MARIM, B.G.; SILVA, D.J.H. da; MATTEDI, A.P.; ALMEIDA, V. de S. Análise de trilha de componentes de produção primários e secundários em tomateiro do grupo Salada. Pesquisa Agropecuária Brasileira, v.45, p.155-162, 2010.

SAS INSTITUTE. SAS/STAT user's guide. Version 8. Cary: SAS Institute, 1999.

SEVERINO, L.S.; SAKIYAMA, N.S.; PEREIRA, A.A.; MIRANDA, G.V.; ZAMBOLIM, L.; BARROS, U.V. Associações da produtividade com outras características agronômicas de café (Coffea arabica L. "Catimor"). Acta Scientiarum. Agronomy, v.24, p.1467-1471, 2002.

WRIGHT, S. Correlation and causation. Journal of Agricultural Research, v.20, p.557-585, 1921.

Recebido em 18 de fevereiro de 2011 e aprovado em 23 de julho de 2012 